\title{
Into the canyons: The phylogeography of the Malagasy frogs Mantella expectata and Scaphiophryne gottlebei in the arid Isalo Massif, and its significance for conservation (Amphibia: Mantellidae and Microhylidae)
}

\author{
Angelica Crottini $^{\mathrm{a}, \mathrm{b}, \mathrm{c}, *}$, Ylenia Chiari ${ }^{\mathrm{e}, 1}$, Vincenzo Mercurio ${ }^{\mathrm{d}}$, Axel Meyer ${ }^{\mathrm{e}}$, \\ Miguel Vences ${ }^{\mathrm{c}}$, Franco Andreone ${ }^{\mathrm{b}}$ \\ ${ }^{a}$ Sezione di Zoologia e Citologia, Dipartimento di Biologia, Universitá degli Studi di Milano, Via Celoria 26, 20133 Milano, Italy \\ ${ }^{\mathrm{b}}$ Museo Regionale di Scienze Naturali, Via G. Giolitti 36, 10123 Torino, Italy \\ ${ }^{Z}$ Zoological Institute, Technical University of Braunschweig, Spielmannstr. 8, 38106 Braunschweig, Germany \\ ${ }^{\mathrm{d}}$ Section Herpetology, Forschungsinstitut und Naturmuseum Senckenberg, Senckenberganlage 25, 60325 Frankfurt a.M., Germany \\ ${ }^{\mathfrak{c}}$ Department of Biology (Evolutionary Biology), University of Konstanz, 78457 Konstanz, Germany
}

\begin{abstract}
Scaphiophryne gottlebei and Mantella expectata are two endemic and threatened frog species that live syntopically in the arid Isalo Massif in southern Madagascar. They share large parts of their distribution areas but differ in their natural history. Scaphiophryne gottlebei is more often found in canyons, while $M$. expectata prefers open habitats. Using samples from their known distribution areas, we investigated the genetic variability of these species by analyzing an approximately 600 base-pair fragment of the mitochondrial cytochrome $b$ gene. Both species include a few widespread and common haplotypes as well as a number of other, geographically restricted ones. However, $M$. expectata exhibits more geographic substructure than $S$. gottlebei, in which one main haplotype represents individuals from various localities across the largest part of the distribution range. Comparing populations inside and outside of the Parc National de l'Isalo showed that the park does not harbour the bulk of the overall genetic diversity of the two species. These results emphasize the importance of so far unprotected habitats for the conservation of genetic variation in the endemic fauna of the Isalo region and of Madagascar in general.
\end{abstract}

Keywords: Scaphiophryne gottlebei; Mantella expectata; Cytochrome $b$; Madagascar; Conservation; Gene flow

\footnotetext{
${ }^{*}$ Corresponding author at: Sezione di Zoologia e Citologia, Dipartimento di Biologia, Universitá degli Studi di Milano, Via Celoria 26, 20133 Milano, Italy. Tel.: + 39250314799 ; fax: +39250314781 .

E-mail address: tiliquait@yahoo.it (A. Crottini).

'Present address: Institut des Sciences de l'Evolution, ISE-M, Université Montpellier, 2 Place Eugène Bataillon, 34095, Montpellier, cedex 5, France.
}

\section{Introduction}

Madagascar is renowned for its unique biota (Goodman and Benstead 2003), which are threatened by habitat destruction and degradation (Myers et al. 2000). Recent zoological studies integrating intensive field surveys and the application of molecular methods have revealed an astonishing degree of microendemism within the 
island, with a few widespread species and many others that are restricted to smaller, sometimes very small ranges. Various hypotheses have been proposed to explain this phenomenon, e.g. isolation within mountain refuges (Raxworthy and Nussbaum 1995), rivers as barriers to gene flow (Pastorini et al. 2003; Louis et al. 2006) or isolation in river drainages (Wilmé et al. 2006). Microendemism presents particular challenges to conservation strategies, which require adequate and simultaneous consideration of a variety of taxa to be representative (Kremen et al. 2008).

While the rainforest of eastern Madagascar is known for its richness in amphibian diversity, comparatively little attention has been paid to the arid areas of Madagascar. Recent analyses have shown that some of the latter are of paramount relevance to the conservation of amphibians (Andreone et al. 2005a). One of them is the Isalo Massif in south-western Madagascar, a huge mass of rocky sandstone crossed by numerous canyons of various length, width and depth (ANGAP 2003; Mercurio et al. 2008) that harbours a comparatively large number of endemic species of amphibians and reptiles (Andreone et al. 2006; Mercurio et al. 2008). Part of the Massif is currently included in the network of protected areas of Madagascar, in the form of the Isalo National Park, one of the country's most important tourist destinations (ANGAP 2003). Most of the natural habitats within the park's boundaries can be considered as relatively safe at present, mainly due to control by park guides and to the fact that the inner parts of the park are difficult to access except by several days of walking. However, human population pressures (e.g. activities related to tourism, land management and sapphire mining) are threatening the areas outside of the park (Duffy 2006).

The outline of Isalo National Park (INP) cannot be considered as a barrier to gene flow, as it largely constitutes an arbitrary, legal border rather than a natural one. Outside of the INP, collecting animals for the pet trade is allowed and habitat degradation is higher, but even inside, close to the borders, there is little control by the authorities, resulting in considerable numbers of illegal fires in the lowlands and illegal wood exploitation in the canyons. For conservation purposes it is therefore relevant to assess which proportion of the genetic diversity of locally endemic species is restricted to the area outside of the park.

Among the 21 species of amphibians found at Isalo (Mercurio et al. 2008), five are currently classified as "endangered" according to IUCN criteria (IUCN 2008) among which: Scaphiophryne gottlebei Busse \& Böhme, 1992 and Mantella expectata Busse \& Böhme, 1992. Both species have been discovered relatively recently (Busse and Böhme 1992), and are likely to be affected by similar threats such as the continuous decline of suitable habitat and overcollection for the pet trade due to their peculiar colouration (Andreone et al. 2005a). The two species are also included in Appendix II of the Convention on the International Trade in Endangered Species (CITES).

Scaphiophryne gottlebei is a mainly nocturnal and fossorial microhylid toad, occurs mainly in rocky pools deep inside the canyons (Mercurio and Andreone 2006), and shows highly seasonal breeding behaviour (Andreone et al. 2006). Because its description was based on specimens supplied by local collectors, the precise distribution range of this species has long remained unknown. Detailed field data have become available only recently, along with new populations discovered mainly in the northeast of the Isalo region (Andreone et al. 2005b).

Mantella expectata is a colourful diurnal frog with alkaloid toxins in its skin (Daly et al. 1996; Vences et al. 1999). In contrast to $S$. gottlebei, individuals of $M$. expectata are only rarely found in deep canyons. These frogs prefer open, sun-exposed areas near the canyons, where temporary small water pools are available (Andreone et al. 2005b, 2006; Mercurio and Andreone 2006; Mercurio et al. 2008). At some sites $M$. expectata occurs in close proximity to, or even in syntopy with, the phylogenetically closely related $M$. betsileo Grandidier, 1872 (Rabemananjara et al. 2007). Although hybridization between these two species has not been documented (Rabemananjara et al. 2007), specimens with apparently intermediate chromatic traits have been observed (Mercurio and Andreone 2006).

Due to the more restricted microhabitat preferences of $S$. gottlebei, its populations can be expected to be more isolated and fragmented than those of $M$. expectata. This could result in more geographically structured genetic variation in $S$. gottlebei. Furthermore, since most populations of $S$. gottlebei had been found in the northern part of the Isalo Massif, together with isolated populations of $M$. expectata with a peculiar reddish colouration, we hypothesized that the geomorphology of the Isalo Massif could have influenced the distribution of these two frog species.

Here we analyse the population-genetic structure of these two microendemic and codistributed frog species as reflected by DNA sequences of a fragment of the mitochondrial cytochrome $b$ gene. We test (1) whether Scaphiophryne gottlebei and Mantella expectata differ in genetic population substructure, and (2) whether the protected area (Isalo National Park) harbours the bulk of the respective genetic variation in these two threatened species or whether other yet unprotected sites are equally or more important for their conservation.

\section{Material and methods}

\section{Sampling localities and tissue samples}

We sampled 104 individuals of $S$. gottlebei from 14 different localities, and 155 specimens of $M$. expectata 
from 25 localities, covering the entire known distribution area of either species. Of these specimens, 15 of $S$. gottlebei and 45 of $M$. expectata (from six and ten populations, respectively) were collected within the boundaries of the INP, whereas 89 of $S$. gottlebei and 110 of $M$. expectata (from eight and fifteen populations, respectively) were collected outside of the protected area (Table 1). Sixteen individuals of S. gottlebei (ca. 16\%) from five different localities (including six individuals from three localities inside the INP), and ten individuals of $M$. expectata (ca. $7 \%$ ) from two localities outside the INP are tadpoles. The remaining tissue samples were obtained by toe-clipping. Tadpoles and toe-clips were collected in January-February and November-December 2004 , and stored in $99 \%$ ethanol. Individuals from several representative localities were collected and preserved as vouchers in the collections of the Museo Regionale di Scienze Naturali (MRSN) in Turin, Italy, and of the Parc Botanique et Zoologique de Tsimbazaza (PBZT) in Antananarivo, Madagascar. Voucher numbers associated with particular sequences obtained can be retrieved from the corresponding GenBank entries (see below).

We divided the sampling localities into two main clusters (Table 1, Fig. 1): (1) populations inside the INP boundaries; and (2) populations outside the park, including llakaka surroundings and nearby areas, as well as six park localities close to or directly along the border of the INP (Tsimanolabero, Malaso, Isalo Oasis, Zahavola, Reine de l'Isalo, and Vohitanana). The latter six localities share with the populations outside the park boundaries an increased risk of habitat alteration, especially where roads are close. The two categories ('inside' and 'outside') also roughly correspond to a northern versus southern subdivision of the populations.

\section{DNA extraction, sequencing and alignment}

Total genomic DNA was extracted from the tissue samples using proteinase $\mathrm{K}(10 \mathrm{mg} / \mathrm{ml})$ digestion followed by a standard salt-extraction protocol (Bruford et al. 1992). We used the primers Cytb-c and CBJ10933 (Bossuyt and Milinkovitch 2000) to amplify a fragment of the mitochondrial cytochrome $b$ gene of ca. 600 nucleotides. Polymerase chain reactions (PCR) were performed in $25 \mu \mathrm{l}$ reactions using ca. $50 \mathrm{ng}$ genomic DNA, $2 \mu \mathrm{l}$ each of $10 \mathrm{pmol}$ primer, $0.5 \mu \mathrm{l}$ of total dNTP $10 \mathrm{mM}$ (Promega), $0.1 \mu \mathrm{l}$ of $5 \mathrm{U} / \mu \mathrm{l} \mathrm{GoTaq}{ }^{\circledR}$, and $5 \mu \mathrm{l}$ $5 \times$ Green GoTaq ${ }^{B}$ Reaction Buffer (Promega). PCR conditions consisted of an initial denaturation step at $94^{\circ} \mathrm{C}$ for $1: 30 \mathrm{~min}, 35$ cycles of denaturation at $94^{\circ} \mathrm{C}$ for $0: 30 \mathrm{~min}$, annealing at $53^{\circ} \mathrm{C}$ for $0: 45 \mathrm{~min}$, followed by an extension at $72{ }^{\circ} \mathrm{C}$ for $1: 30 \mathrm{~min}$, and a final extension at $72^{\circ} \mathrm{C}$ for $10 \mathrm{~min}$. PCR products were loaded on $1 \%$ agarose gels, stained with ethidium bromide, and visualised on a "Gel Doc" system (PeqLab). If results were satisfying, products were purified using QIAquick spin columns (Qiagen). The heavy mtDNA strands were sequenced using an ABI $3730 \mathrm{XL}$ automated sequencer (Macrogen Inc.). Sequences were edited manually and unambiguously aligned using the BioEdit sequence alignment editor, ver. 7.0.5 (Hall 1999). The number of base substitutions was determined using MEGA, ver. 4 (Kumar et al. 2008). Sequences were merged into haplotypes using the online application DNAcollapser ver. 1.0 (http://www.birc.au.dk/fabox/). All newly determined sequences have been deposited in GenBank (accession numbers: EF674586-EF674840).

\section{Exclusion of deviant sequences}

After a first exploratory reconstruction of cytochrome $b$ haplotype networks, two sequences initially assigned to $S$. gottlebei and seven sequences initially assigned to $M$. expectata clustered outside the respective networks. The two sequences of $S$. gottlebei, determined from two tadpoles sampled at two different localities, were strongly differentiated from the other $S$. gottlebei sequences (minimum distance: 16 substitutions). In a phylogenetic analysis of cytochrome $b$ sequences of all Scaphiophryne species (not presented here), these two sequences resulted as the sister clade to $S$. gottlebe $i$ s. str. Two cytochrome $b$ sequences of $M$. expectata originating from the southernmost part of the study region represented an entity different from the $M$. expectata and $M$. betsileo networks, and differed from the $M$. expectata haplotype "E13" by 16 substitutions.

Following the protocol of Vences et al. (2000), we sequenced a fragment of $540 \mathrm{bp}$ of the 16S rRNA gene, which is known to have highly invariable priming sites in amphibians (Vences et al. 2005). This fragment confirmed that the above-mentioned individuals fall outside of the respective species clusters (GenBank accession numbers: EF674841-EF674851). Further analysis resulted in (1) five of these individuals being assigned to Mantella betsileo, (2) one haplotype (two sequences) initially assigned to $M$. expectata being placed as sister to $M$. expectata s. str., and (3) the two Scaphiophryne specimens with deviant cytochrome $b$ haplotypes as sister to $S$. gottlebei. Remarkably, the five specimens with $M$. betsileo haplotypes did not show any relevant difference in colouration from syntopic specimens phenotypically ascribed to $M$. expectata, suggesting introgression or incomplete lineage sorting for these haplotypes. In the latter two cases, we cannot exclude the existence of closely related, sibling species, but clarification of this point is beyond the objectives of the present paper. Hence, because species attribution of all these deviant sequences is uncertain, they were excluded from the following analyses. 
Table 1. Sample data and mitochondrial haplotype designations for populations of Scaphiophryne gottlebei (S. got.) and Mantella expectata (M. exp.) in the area of Isalo National Park (INP), Madagascar

\begin{tabular}{|c|c|c|c|c|c|c|c|c|c|}
\hline \multirow[t]{2}{*}{ Locality/population } & \multirow[t]{2}{*}{ Latitude (S) } & \multirow[t]{2}{*}{ Longitude (E) } & \multirow[t]{2}{*}{ INP grp. } & \multicolumn{2}{|c|}{ Sample size } & \multicolumn{2}{|l|}{ Haplotypes } & \multicolumn{2}{|l|}{$I I$} \\
\hline & & & & S. got. & $M$ exp. & S. got. & M. exp. & S. got. & M. exp. \\
\hline Ambatovaky & $23^{\circ} 24.18^{\prime}$ & $45^{\circ} 06.16^{\prime}$ & Out & - & $\therefore 2$ & - & 2 (E11, E12) & -. & 0.00332 \\
\hline Ambovo & $22^{\circ} 30.48^{\prime}$ & $45^{\circ} 21.15^{\prime}$ & In & 2 & 5 & $1(\mathrm{~S} 1)$ & $3(\mathrm{E} 1-\mathrm{E} 3)$ & 0 & 0.00166 \\
\hline Amparambatomavo & $22^{\circ} 18.11^{\prime}$ & $45^{\circ} 21.36^{\prime}$ & In & 4 & 2 & $1(\mathrm{~S} 1)$ & $2(\mathrm{E} 2, \mathrm{E} 3)$ & 0 & 0.00166 \\
\hline Ampasibe & $23^{\circ} 02.35^{\prime}$ & $45^{\circ} 16.57^{\prime}$ & Out & - & 7 & $-\quad$. & 4 (E1, E8, E10, E15) & - & 0.00221 \\
\hline Andohaosy & $22^{\circ} 31.00^{\prime}$ & $45^{\circ} 20.00^{\prime}$ & In & - & 2 & - & 1 (E3) & - & 0 \\
\hline Andohasahenina & $22^{\circ} 50.00^{\prime}$ & $45^{\circ} 11.28^{\prime}$ & Out & 35 & 3 & $3(\mathrm{~S} 1, \mathrm{~S} 2, \mathrm{~S} 4)$ & 3 (E1, E5, E7) & 0.00133 & 0.00332 \\
\hline Andranombilahy & $22^{\circ} 48.51^{\prime}$ & $45^{\circ} 14.16^{\prime}$ & Out & 1 & - & $1(\mathrm{~S} 2)$ & - & nc & - \\
\hline Andranomena & $22^{\circ} 44.41^{\prime}$ & $45^{\circ} 16.50^{\prime}$ & Out & 7 & 19 & $2(\mathrm{~S} 1, \mathrm{~S} 2)$ & $3(\mathrm{E} 1, \mathrm{E} 5, \mathrm{E} 8)$ & 0.00078 & 0.00091 \\
\hline Antambonoa & $22^{\circ} 22.31^{\prime}$ & $45^{\circ} 17.46^{t}$ & In & 1 & 5 & $1(\mathrm{~S} 1)$ & $2(\mathrm{E} 2, \mathrm{E} 3)$ & $\mathrm{nc}$ & 0.00100 \\
\hline Bemenara & $22^{\circ} 48.07^{\prime}$ & $45^{\circ} 15.00^{\prime}$ & Out & 9 & 6 & $4(\mathrm{~S} 1-\mathrm{S} 3, \mathrm{~S} 5)$ & 5 (E1, E6, E7, E10, E13) & 0.00183 & 0.00310 \\
\hline Bevato & $22^{\circ} 30.36^{\prime}$ & $45^{\circ} 21.35^{\prime}$ & In & 2 & - & $1(\mathrm{~S} 1)$ & $-\infty$ & 0 & - \\
\hline Grotte des Portugais & $22^{\circ} 18.06^{\prime}$ & $45^{\circ} 18.37^{\prime}$ & In & -. & 1 & - & $1(\mathrm{E} 2)$ & - & ne \\
\hline Iambahatsy & $22^{\circ} 24.35^{\prime}$ & $45^{\circ} 16.13^{\prime}$ & In & - & 8 & - & 3 (E1-E3) & - & 0.00160 \\
\hline Isalo Oasis & $22^{\circ} 37.37^{\prime}$ & $45^{\circ} 21.12^{\prime}$ & Out & - & 4 & - & $2(\mathrm{E} 1, \mathrm{E} 15)$ & - & 0.00083 \\
\hline Lola & $22^{\circ} 55.54^{\prime}$ & $45^{\circ} 19.48^{\prime}$ & Out & 4 & 10 & $3(\mathrm{~S} 1, \mathrm{S6}, \mathrm{S} 7)$ & $2(\mathrm{E} 1, \mathrm{E} 5)$ & 0.00165 & 0.00059 \\
\hline Malaso & $22^{\circ} 35.31^{\prime}$ & $45^{\circ} 21.32^{\prime}$ & Out & 7 & 8 & 5 (S1, S8-S11) & $3(\mathrm{E} 1, \mathrm{E} 2, \mathrm{E} 15)$ & 0.00235 & 0.00113 \\
\hline Morahariva & $22^{\circ} 46.12^{\prime}$ & $45^{\circ} 18.42^{\prime}$ & Out & - & 10 & - & $3(\mathrm{E} 1, \mathrm{E} 5, \mathrm{E} 9)$ & - & 0.00126 \\
\hline Petit Nazareth & $22^{\circ} 33.25^{\prime}$ & $45^{\circ} 21.23^{\prime}$ & In & 3 & 3 & $2(\mathrm{SI}, \mathrm{S} 11)$ & $2(\mathrm{E} 1, \mathrm{E} 3)$ & 0.00110 & 0.00221 \\
\hline Reine de l'Isalo & $22^{\circ} 37.41^{\prime}$ & $45^{\circ} 20.38^{\prime}$ & Out & -- & 2 & - & $1(\mathrm{E} 1)$ & $-\ldots$ & 0 \\
\hline Sahanafa* & $22^{\circ} 18.35^{\prime}$ & $45^{\circ} 17.48^{\prime}$ & In & - & 3 & - & $2(\mathrm{E} 2, \mathrm{E} 3)$ & -. & 0.00111 \\
\hline Sakamalio & $22^{\circ} 26.09^{\prime}$ & $45^{\circ} 15.31^{\prime}$ & In & -. & 5 & - & $3(\mathrm{E} 2-\mathrm{E} 4)$ & - & 0.00199 \\
\hline Sakavato* & $23^{\circ} 29.01^{\prime}$ & $44^{\circ} 56.09^{\prime}$ & Out & - & 1 & - & $1(\mathrm{E} 10)$ & $\ldots$ & nc \\
\hline Tsianerena* & $22^{\circ} 52.38^{\prime}$ & $45^{\circ} 18.26^{\prime}$ & Out & - & 6 & - & $1(\mathrm{E} 1)$ & - & 0 \\
\hline Tsimanolabero & $22^{\circ} 34.59^{\prime}$ & $45^{\circ} 23.00^{\prime}$ & Out & - & 4 & - & 2 (EI, EI6) & $\ldots$ & 0.00083 \\
\hline Tsiombivositra & $22^{\circ} 18.15^{\prime}$ & $45^{\circ} 21.50^{\prime}$ & In & 2 & 8 & $1(S 1)$ & $2(\mathrm{E} 2, \mathrm{E} 3)$ & 0 & 0.00071 \\
\hline Vohitanana & $22^{\circ} 38.12^{\prime}$ & $45^{\circ} 20.46^{\prime}$ & Out & 1 & 3 & $1(\mathrm{SI})$ & 1 (E1) & $\mathrm{ne}$ & 0 \\
\hline Zahavola & $22^{\circ} 37.38^{\prime}$ & $45^{\circ} 21.52^{\prime}$ & Out & 24 & 21 & $1(\mathrm{~S} 1)$ & 4 (E1, E5, E14, E15) & 0 & 0.00095 \\
\hline Total & & & & 102 & 148 & 11 & 16 & 0.00127 & 0.00202 \\
\hline
\end{tabular}

Locality names as given by local people, thus unofficial. Asterisks denote populations of $M$. expectata found in syntopy with $M$. betsileo. INP grp. = assignment to locality grouping 'inside' or 'outside' the park (see text). Number of haplotypes found per locality and species followed by corresponding haplotype designation(s) in parenthesis. $I I=$ nucleotide diversity according to Nei (1987); $\mathrm{nc}=$ not calculated. Samples not used for phylogeographic analyses (deviant haplotypes) not included.
(19tide 


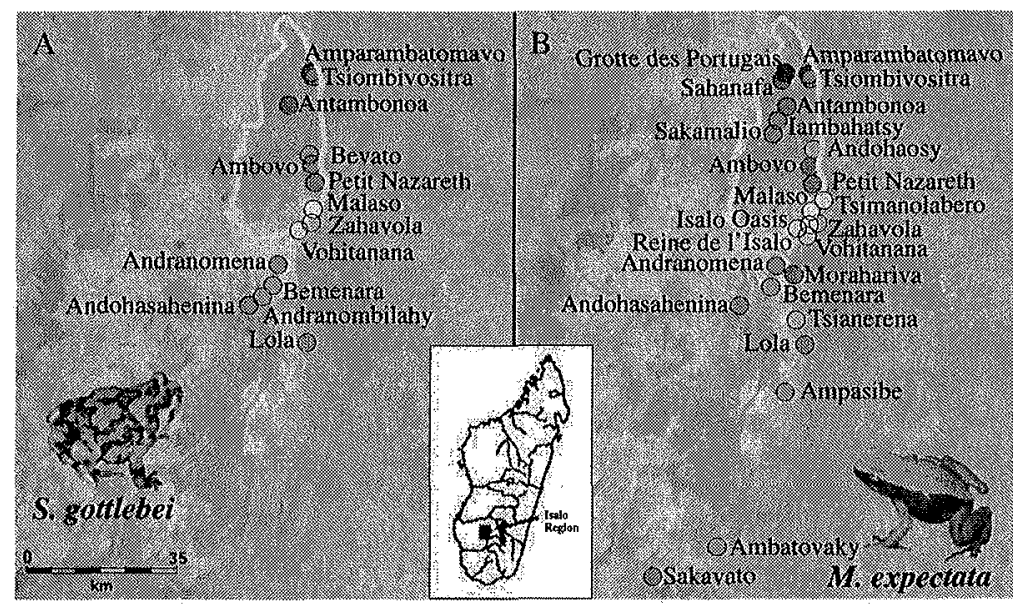

Fig. 1. Sampling localities for Scaphiophryne gottlebei (A) and Mantella expectata (B), representing the respective reliably known distribution areas, as records of $M$. expectata from near Toliara and Morondava, and from Mikea forest, require confirmation (Vences et al. 1999; Rabemananjara et al. 2007). Outline of Isalo National Park shown in yellow; inset: location of Isalo Massif in Madagascar. Colors of localities are as in the haplotype networks in Fig. 2.

\section{Haplotype network reconstruction and nucleotide diversity}

We used the program TCS, ver. 1.21 (Clement et al. 2000), to reconstruct haplotype networks for the two frog species studied. This software employs the method of Templeton et al. (1992), calculates the number of mutational steps by which each haplotype pair differs, and computes the probability of parsimony for pairwise differences until the probability exceeds 0.95 .

For both species, nucleotide diversity (II) according to Nei (1987) and the average number of nucleotide differences per site between sequences were calculated, for the full data sets and separately for samples from inside and outside the INP, using DNASP software, ver. 4.50.3 (Rozas et al. 2003). We compared nucleotide diversity within and between species using Mann-Whitney $U$-tests (run with KyPlot software, ver. 1.0 beta 7; Yoshioka 2002). Specifically, we tested (1) all $S$. gottlebei populations inside the park vs. those outside, (2) all $M$. expectata populations inside the park vs. those outside, and (3) all $S$. gottlebei vs. all $M$. expectata populations.

\section{Mismatch distribution and gene flow}

Episodes of population growth and decline leave characteristic signatures in the distribution of pairwise nucleotide differences between populations (Rogers and Harpending 1992). However, there are no obvious reasons to assume that $S$. gottlebei and $M$. expectata are affected by significant growth or decline of population size. Thus, we compared the empirical mismatch distributions within the two subgroups (inside and outside the INP) and within species under the assumption of constant population size, using DNASP.

To quantify the extent of genetic divergence between the populations inside and outside the INP, we used Arlequin, ver. 3.1 (Excoffier et al. 2005), to compute the genetic distances by means of a comparison between allele frequencies. For this purpose we applied the Fst (Fixation Index) values (using the corrected version as defined by Weir and Cockerham 1984) as a measure of the average level of gene flow. The test of significance for the Fst was carried out on 1000 permutations of the data.

\section{Isolation by distance}

Population coordinates were collected by GPS in the field, then converted to a decimal-degree (Deg Dec) format suitable for further analysis using the coordinate converter available at http://www.fcc.gov/mb/ audio/bickel/DDDMMSS-decimal.html. Using Pathmatrix, ver. 1.1 (Ray 2005), a GIS tool based on a least-cost path algorithm, and providing the list of populations and appropiate Deg Dec coordinates, we computed matrices of effective geographic distances among populations, using Euclidean distances.

Isolation by distance (IBD) is defined as the accumulation of genetic differentiation with increased geographical distance, resulting from restricted dispersal if compared with the geographic range (Wright 1943). IBD analyses were run using the IBD Web Service (Jensen et al. 2005). This approach allows testing whether there is a correlation between genetic distances and geographic distances, using Mantel tests. Analyses were performed for each species separately, using values 
of Fst as proxies for genetic distances (DNA distance method: haplotypes equidistant); data were permuted 30,000 times to estimate the $99 \%$ upper tail probability of the matrix correlation coefficients. The correlation coefficient $(r)$ indicates the degree of correlation between geographical and genetic distances. The probability value $(P<0.001)$ indicates that correlation coefficients are significantly different from 0 .

A limitation of this program is the fact that a maximum of one population may contain a single individual. We therefore excluded from these analyses two singlespecimen populations of $S$. gottlebei (Andranombilahy and Vohitanana) and one of $M$. expectata (Grotte des Portugais).

\section{Results}

\section{Alignment characteristic, nucleotide diversity and mismatch distribution}

Alignment of sequences was straightforward. We did not detect any gaps, and translation into amino acids resulted in neither nonsense nor stop codons. In Mantella expectata 17 sites out of 603 used for analyses $(2.82 \%)$ were variable, with eight being parsimonyinformative, and the empirical base frequencies were $\pi_{\mathrm{A}}=0.269, \pi_{\mathrm{C}}=0.283, \pi_{\mathrm{G}}=0.126, \pi_{\mathrm{T}}=0.321$. In S. gottlebei 11 sites out of 615 used for analyses $(1.79 \%)$ were variable, but just four were parsimonyinformative, and the empirical base frequencies were $\pi_{\mathrm{A}}=0.252, \pi_{\mathrm{C}}=0.329, \pi_{\mathrm{G}}=0.137, \pi_{\mathrm{T}}=0.282$.

In $M$. expectata and $S$. gottlebei we identified 16 and 11 haplotypes, respectively. The $\Pi$ of Nei (1987) was not significantly different between the populations sampled inside and outside the INP (Mann-Whitney $U$-test; $P>0.05)$ in $M$. expectata, but was significant in $S$. gottlebei (Mann-Whitney $U$-test; $P<0.05$ ). When comparing the $\Pi$ values between the two species (considering all populations within each species), we found $S$. gottlebei to have less genetic diversity than $M$. expectata (Table 2), but the difference was not statistically significant (Mann-Whitney $U$-test; $P>0.05$ ). Probably because of their small distribution area and of their large codistribution, the raggedness of empirical mismatch distributions within regions and within species suggests that there is no difference in population history between these two species. Under all conditions tested we found congruence with a distribution under constant population size.

\section{Haplotype networks}

The haplotype network constructed from sequences of $S$. gottlebei (Fig. 2A) shows that haplotype $\mathrm{S} 1$ is
Table 2. Diversity indices for partial cytochrome $b$ gene in Scaphiophryne gottlebei and Mantella expectata from inside and outside of Isalo National Park (INP), Madagascar

\begin{tabular}{lrrrrr}
\hline Population & $n$ loc & $n$ ind & $n$ hap & $\Pi$ & $\operatorname{sd}(\Pi)$ \\
\hline$S$. gottlebei & & & & & \\
Inside INP & 6 & 14 & 2 & 0.00023 & 0.00019 \\
Outside INP & 8 & 88 & 11 & 0.00138 & 0.00016 \\
Total & 14 & 102 & 11 & 0.00127 & 0.00015 \\
$M$. expectata & & & & & \\
Inside INP & 10 & 42 & 4 & 0.00150 & 0.00018 \\
Outside INP & 15 & 106 & 14 & 0.00145 & 0.00017 \\
Total & 25 & 148 & 16 & 0.00202 & 0.00016 \\
\hline
\end{tabular}

$n$ loc $=$ number of localities; $n$ ind $=$ number of individuals; $n$ hap $=$ numbers of haplotypes; $\Pi=$ nucleotide diversity according to Nei (1987); $\operatorname{sd}(I)=$ standard deviation of nucleotide diversity

distributed over the species' entire distribution range. Except for haplotype S2, occurring at four southern localities, and S11, occurring at Malaso and Petit Nazareth, all haplotypes are locally restricted, and differ from S1 by just one or two substitutions. Inside the park we were able to identify just two haplotypes (S1 and S11), while the highest mitochondrial genetic variability of the species is found outside the INP. In particular, the haplogroup consisting of haplotypes S2-S5 is restricted to the southernmost part of the species' range, while the locally derived haplotypes S6-S10 are found only at two localities: Lola and Malaso.

The haplotype network of $M$. expectata (Fig. 2B) shows a partly different pattern. One haplotype, $E 1$, is well distributed and widespread but mainly occurs outside the park, with the exception of three populations inside the park borders: Ambovo, Andohaosy and Petit Nazareth. In the haplogroup E2-E4, haplotypes E2 and E3 basically occur in all populations inside the park, whereas $\mathrm{E} 4$ is restricted to the single locality of Sakamalio, but again inside the park. In contrast, in the populations outside the park, haplotypes E2 and E3 are almost absent, with the only exception of Malaso, a locality placed on the park border, where we found haplotype E2. Besides haplotype E1, just three more haplotypes are distributed across the entire region: E5, E10 and E15. All other haplotypes are locally restricted and occur at only one or two localities outside the park. Therefore, the highest genetic variability is found in the south, outside the INP boundaries, where all haplotypes except E4 occur.

\section{Gene flow and isolation by distance}

In the permutation test all Fst values resulted significantly different from zero, and the obtained measure of population differentiation $(F s t=0.31162)$ 
A

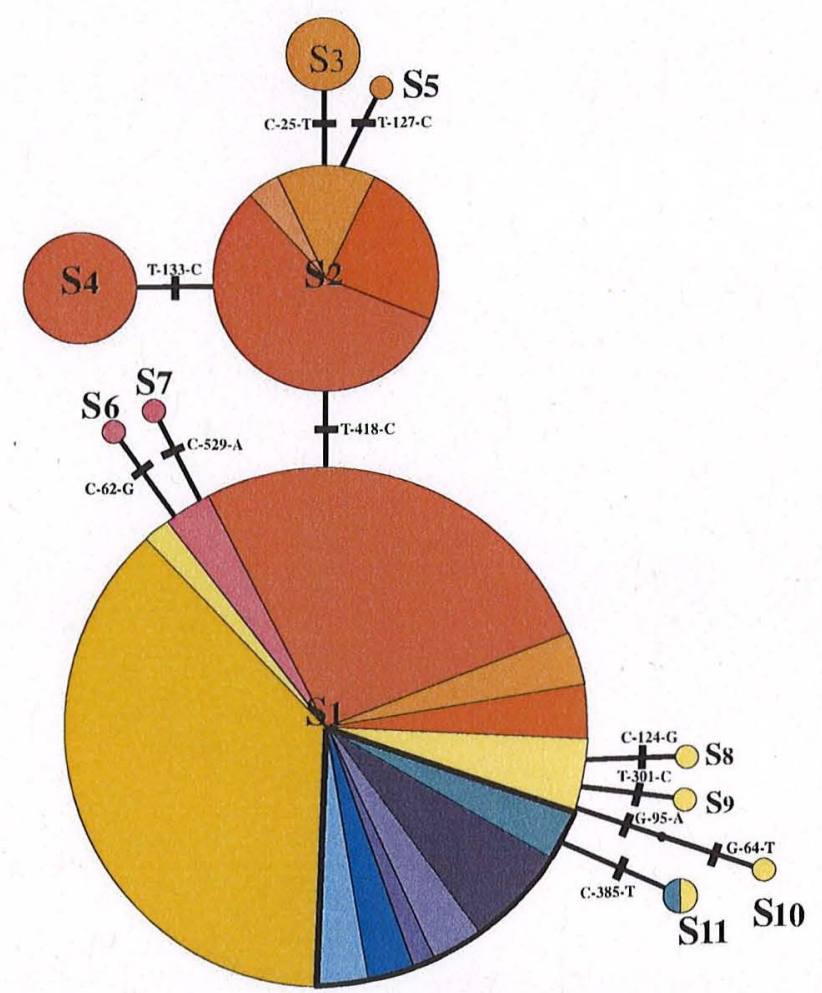

Ambatovaky

Ambovo

- Amparambatomavo

口 Ampasibe

$\square$ Andohaosy

믐 Andohasahenina

$\square$ Andranombilahy

Andranomena

- Antambonoa

$\square$ Bemenara

回 Bevato

- Grotte des Portugais

Iambahatsy

$\square$ Isalo Oasis

回 Lola

$\square$ Malaso

口orahariva

- Petit Nazareth

$\square$ Reine de l'Isalo

- Sahanafa

- Sakamalio

심 Sakavato

$\square$ Tsianerena

$\square$ Tsimanolabero

- Tsiombivositra

$\square$ Vohitanana

$\square$ Zahavola

B
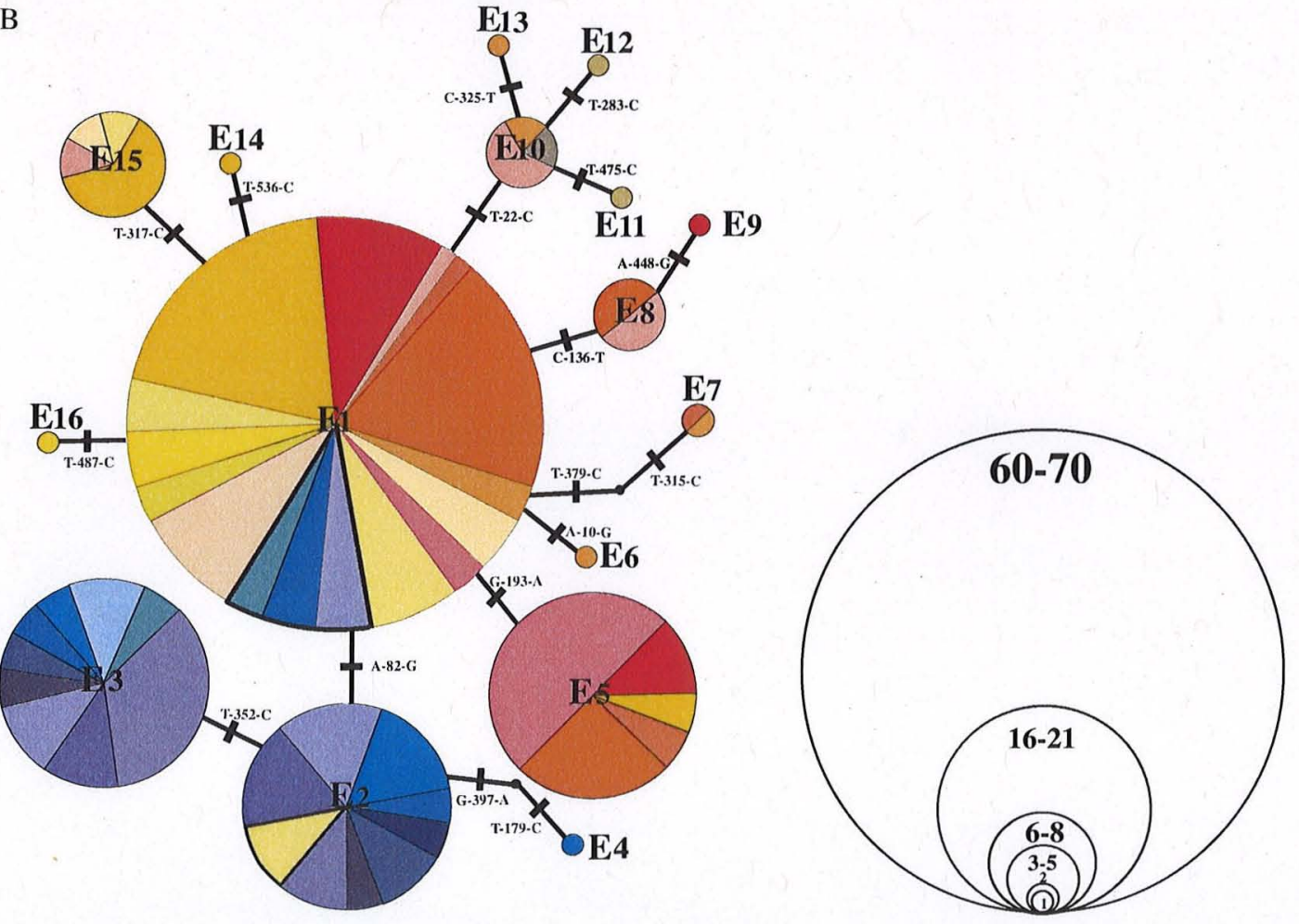

Fig. 2. Haplotype networks based on the analysis of a fragment of mitochondrial cytochrome $b$ gene: (A) Scaphiophryne gottlebei; $615 \mathrm{bp}$ and (B) Mantella expectata; $603 \mathrm{bp}$. Circle size proportional to number of individuals sharing a given haplotype. Black bars represent single nucleotide substitutions. Localities inside Isalo National Park shown in different shades of blue, those outside INP in different shades of yellow, orange or brown. Within circles, thick black lines separate localities inside and outside Isalo National Park. 
indicates relatively high gene flow between the two groups of populations of $S$. gottlebei, a result that certainly is largely influenced by the wide distribution of haplotype $\mathrm{S} 1$. The situation is different for $M$. expectata populations, for which the relatively high Fst value (Fst $=0.57659$ ) suggests the existence of only limited gene flow between populations inside and outside the INP. This result is well supported by the almost exclusive presence of haplotypes E2-E4 inside the park, where the remaining haplotypes (except for E1) are missing.

In $S$. gottlebei the correlation between genetic and geographic distance resulted as not significantly different from $0(p=0.3675 ; Z=24.3510 ; r=0.0411)$. The correlation coefficient was significantly different from 0 $(p<0.001)$ in the IBD analysis of $M$. expectata, but the correlation between genetic and geographic distance was still weak $(\mathrm{Z}=3,582,562.0368 ; r=0.3951)$.

\section{Discussion}

We found different patterns of mitochondrial variability in the two studied species. Overall, $S$. gottlebei shows a lower number of haplotypes and lower nucleotide diversity than $M$. expectata, although the difference between the nucleotide diversities was not statistically significant. In $S$. gottlebei a single haplotype was dominant in all populations, and several of the other haplotypes occurred in single individuals only, thus probably representing are haplotypes. In contrast, $M$. expectata had a stronger substructuring of populations, with particular haplotypes being common in either northern or southern populations, and a significant (though weak) trend of isolation by distance. These data roughly fit the previous prediction by Vences et al. (2002), who had related the low substitution rate found in all species of Scaphiophryne to their pond breeding habit and their presumed higher dispersal ability, which would counteract the fixation of more local haplotypes. The habitat specialization observed in S. gottlebei (Andreone et al. 2005b, 2006; Mercurio and Andreone 2006) at first glance contradicts the notion of a relatively mobile species, but very few direct observations on this aspect are available. If our inference of high gene flow among $S$. gottlebei populations is correct, then migration events likely take place during the often heavy and long-lasting rainfalls of the austral summer, which coincide with the toads' short breeding season. In this sense, the synchrony of the breeding period of $S$. gottlebei individuals can play a key role in the maintenance of high gene flow between populations. This statement is reinforced by our sightings, during some stormy days, of adults moving in open spaces far away from any water bodies, and of tadpoles washed away after heavy rains.
The low mitochondrial variation observed in $S$. gottlebei theoretically could also be due to other factors. For example, sampling may have been biased by the presence of populations represented only by tadpoles (with individuals that could be part of the same clutch). However, the effect of such a possible sampling bias is very small, as our study includes samples from many different localities, with only a small proportion of tadpoles and a higher number of adult individual from each population. Additionally, S. gottlebei has a more restricted distribution and shows stronger genetic isolation than $M$. expectata. Although both species are currently considered as Isalo endemics, $M$. expectata-like forms are known from several localities in western Madagascar, thus gene flow between populations from outside the Isalo region may occur. Moreover, processes of hybridization with the closely related and partly syntopic forms $M$. aff. expectata and $M$. betsileo may also occur, leading to higher mitochondrial variation. In contrast, no populations of Scaphiophryne species similar to $S$. gottlebei are known from outside the Isalo region, and due to the tetraploidy in $S$. gottlebei, hybridization with other species or gene flow with populations from outside the Isalo region are very unlikely. Thus, bottleneck effects in . this area could reduce the genetic variability of this species more easily than in $M$. expectata.

In $S$ gottlebei we also detected a lower genetic diversity in populations inside the park, where across six localities we found only two haplotypes. It was not possible to determine whether this difference between northern and southern populations is due to the imbalance in numbers of individuals belonging to inside versus outside populations. However, it is worth noting that one fourth of the $S$. gottlebei samples used for the analyses came from Zahavola (24 individuals), a site on the park's border (here grouped as 'outside' of the INP), where all individuals share the same haplotype: the widely distributed $\mathrm{S} 1$.

In contrast, based on field observations, adult individuals of Mantella expectata may be more philopatric, migrate less and be more restricted to the areas along the temporary streams where they breed. This biological difference could lead to somewhat more restricted gene flow between populations inside and outside the park. Mantella expectata individuals from northern and southern populations also differ in phenotype, with more reddish dorsal colouration in the north versus bright yellow in the south, whereas in the southernmost populations, such as Sakavato, an additional colour morph was recorded, showing a less bright yellow dorsum and some intermediate chromatic traits (e.g. presence of diamond-shaped markings on the back, usually present in $M$. betsileo and absent in all other $M$. expectata observed in the field.

From a conservation perspective, it is relevant that Isalo National Park harbours only part of the genetic 
diversity of Scaphiophryne gottlebei and Mantella expectata. Especially in $M$. expectata, the southern populations (outside of the INP) are genetically distinct and, if the colour differences prove to be consistent, they deserve to be considered as distinct management units for future conservation efforts. In $S$, gottlebei all haplotypes are found in southern populations, although one population with three unique haplotypes (Malaso) is found just at the park boundary. Although receiving some protection, this and other peripheral populations most likely are under heavier anthropogenic pressure than those deep inside the protected area. Our results highlight the importance of the currently unprotected populations of both species, i.e. those outside of Isalo National Park, for conserving genetic diversity in $S$. gottlebei and $M$. expectata. The whole Isalo Massif would need to be included in the park to preserve the genetic diversity of the analysed species. Streams and spring ponds in arid areas are often under threat, because water can be drained for human usage. Also, there is a high risk that uncontrolled sapphire-mining activities could expand into some of these areas. Therefore, the natural water bodies near Isalo, populated by $S$. gottlebei and/or $M$. expectata, should receive particular attention in conservation efforts (Andreone et al. 2008) if in the future this area is further developed for tourism or if mining activities are to be expanded.

\section{Acknowledgments}

We are grateful to G. Aprea, F. Mattioli, J.E. Randrianirina and T.J. Razafindrabe for their help in the field, and to F. Muenzel, $O$. Jovanović, K. Wollenberg and M. Kondermann for their assistance in the laboratory. A.C. is especially grateful to M. Ferraguti for the opportunity to work on this project. F.A.'s and V.M.'s work in Madagascar was made possible by a collaboration agreement between the Parc Botanique et Zoologique de Tsimbazaza and the Museo Regionale di Scienze Naturali, Torino, and was supported by the Nando Peretti Foundation, the National Amphibian Conservation Center, the Declining Amphibian Population Task Force/IUCN (Seed Grants and Rapid Response Fund), by the Madagascar Fauna Group, Conservation International, and the Wildlife Conservation Society. Y.C. was supported by a fellowship from the Landesgraduiertenförderung Baden-Württemberg. This is the publication ISEM 2008-066 by Y.C. The molecular work was supported by grants from the Deutsche Forschungsgemeinschaft to A.M. and M.V. and from the Volkswagen Foundation to M.V. We are indebted to the Malagasy authorities, especially to the Association National des Aires Protegées (ANGAP) and the Ministère de l'Environnement, des Eaux et Forêts, for issuing research permits. We sincerely thank the two anonymous reviewers; their comments helped to improve the paper.

\section{References}

Andreone, F., Cadle, J.E., Glaw, F., Nussbaum, R.A., Raxworthy, C.J., Vallan, D., Vences, M., 2005a. Species review of amphibian extinction risks in Madagascar: conclusions from the Global Amphibian Assessment. Conserv. Biol. 19, 1790-1802.

Andreone, F., Mercurio, V., Mattioli, F., Razafindrabe, T.J., $2005 \mathrm{~b}$. Good news for three critically endangered and traded frogs from Madagascar. Froglog $72,2$.

Andreone, F., Mercurio, V., Mattioli, F., 2006. Between environmental degradation and international pet trade: conservation strategies for the threatened amphibians of Madagascar. Natura (Soc. It. Sci. Nat. Mus. Civ. Stor. Nat. Milano) 95, 81-96.

Andreone, F., Carpenter, A.I., Cox, N., Preez, L.du., Freeman, K., Furrer, S., Garcia, G., Glaw, F., Glos, J., Knox, D., Köhler, J., Mendelson III., J.B., Mercurio, V., Mittermeier, R.A., Moore, R.D., Rabibisoa, N.H.C., Randriamahazo, H., Randrianasolo, H., Rasoamampionona Raminosoa, N., Ravoahangimalala Ramilijaona, $\mathbf{O}$., Raxworthy, C.J., Vallan, D., Vences, M., Vieites, D.R., Weldon, C., 2008. The challenge of conserving amphibian megadiversity in Madagascar. PLoS Biol. 6 (5), el18.

ANGAP (Association Nationale pour la Gestion des Aires Protegées), 2003. Plan de Gestion du Réseau National des Aires Protégées de Madagascar, version révisée. ANGAP and Ministère de l'Environnement, Antananarivo.

Bossuyt, F., Milinkovitch, M.C., 2000. Convergent adaptive radiations in Madagascan and Asian ranid frogs reveal covariation between larval and adult traits. Proc. Natl. Acad. Sci. USA 97, 6585-6590.

Bruford, M.W., Hanotte, O., Brookfield, J.F.Y., Burke, T. 1992. Single-locus and multilocus DNA fingerprint. In: Hoelzel, A.R. (Ed.), Molecular Genetic Analysis of Populations: A Practical Approach. IRL Press, Oxford, pp. 225-270.

Busse, K., Böhme, W., 1992. Two remarkable frog discoveries of the genera Mantella (Ranidae: Mantellinae) and Scaphiophryne (Microhylidae: Scaphiophryninae) from the west coast of Madagascar. Rev. Fr. Aquariol. 19, 57-64.

Clement, M., Posada, D., Crandall, K.A., 2000. TCS: a computer program to estimate gene genealogies. Mol. Ecol. 9, 1657-1659.

Daly, J.W., Andriamaharavo, N.R., Andriantsiferana, M., Myers, C.W., 1996. Madagascan poison frogs (Mantella) and their skin alkaloids. Am. Mus. Novit. 3177, 1-34.

Duffy, R., 2006. Global environmental governance and the challenge of shadow states: the impact of illicit sapphire mining in Madagascar. Dev. Change 36, 825-843.

Excoffier, L., Laval, G., Schneider, S., 2005. Arlequin ver. 3.0: an integrated software package for population genetics data analysis. Evol. Bioinf. Online 1, 47-50.

Goodman, S.M., Benstead, J.P., 2003. The Natural History of Madagascar. Chicago University Press, Chicago and London. 
Hall, T.A., 1999. BioEdit: a user-friendly biological sequence alignment editor and analysis program for Windows $95 / 98 /$ NT. Nucleic Acids Symp. 41, 95-98. [Downloaded on 5 September 2006 from: 〈http://www.mbio.ncsu.edu/ BioEdit/bioedit.html $>$ ].

IUCN (International Union for Conservation of Nature), 2008. 2008 IUCN Red List of Threatened Species. [Downloaded on 26 October 2008 from: 〈www.iucnredlist.org >].

Jensen, J.L., Bohonak, A.J., Kelley, S.T., 2005. Isolation by distance, web service. BMC Genet. 6, 13 (Version 3.14 available at: 〈http://ibdws.sdsu.edu/ $\rangle$ ).

Kremen, C, Cameron, A., Moilanen, A., Phillips, S.J., Thomas, C.D., Beentje, H., Dransfield, J., Fisher, B.L., Glaw, F., Good, T.C., Harper, G.J., Hijmans, R.J., Lees, D.C., Louis Jr., E., Nussbaum, R.A., Raxworthy, C.J., Razafimpahanana, A., Schatz, G.E., Vences, M., Vieites, D.R., Zjhra, M.L., 2008. Aligning conservation priorities across taxa in Madagascar with high-resolution planning tools. Science 320, 222-226.

Kumar, S., Dudley, J., Nei, M., Tamura, K., 2008. MEGA: A biologist-centric software for evolutionary analysis of DNA and protein sequences. Brief. Bioinf. 9, 299-306.

Louis Jr., E., Engberg, S.E., Lei, R., Geng, H., Sommer, J.A., Randriamampionona, R., Randriamanana, J.C., Zaonarivelo, J.R., Andriantompohavana, R., Randria, G., Prosper, Ramaromilanto, B., Rakotoarisoa, G., Rooney; A., Brenneman, R.A., 2006. Molecular and morphological analyses of the sportive lemurs (family Megaladapidae: genus Lepilemur) reveals 11 previously unrecognized species. Spec. Publ. Texas Tech. Univ. 49, 1-47.

Mercurio, V., Andreone, F., 2006. The tadpoles of Scaphiophryne gottlebei (Microhylidae, Scaphiophryninae) and Mantella expectata (Mantellidae, Mantellinae) from Isalo Massif, central-southern Madagascar. Alytes 23, 81-95.

Mercurio, V., Aprea, G., Crottini, A., Mattioli, F., Randrianirina, J.E., Razafindrabe, T.J., Andreone, F., 2008. The amphibians of Isalo Massif, southern-central Madagascar: high frog diversity in an apparently hostile dry habitat. In: Andreone, F., Randriamahazo, H. (Eds.), A Conservation Strategy for the Amphibians of Madagascar. Monogr. Mus. Reg. Sci. Nat. Torino 45, 143-196.

Myers, N., Mittermeier, R.A., Mittermeier, C.G., Fonseca, G.A.B.de., Kent, J., 2000. Biodiversity hotspots for conservation priorities. Nature 403, 853-858.

Nei, M., 1987. Molecular Evolutionary Genetics. Columbia University Press, New York.

Pastorini, J., Thalmann, U., Martin, R.D., 2003. A molecular approach to comparative phylogeography of extant Malagasy lemurs. Proc. Natl. Acad. Sci. USA 100, 5879-5884.

Rabemananjara, F.C.E., Crottini, A., Chiari, Y., Andreone, F., Glaw, F., Duguet, R., Bora, P., Ravoahangimalala
Ramilijaona, O., Vences, M., 2007. Molecular systematics of Malagasy poison frogs in the Mantella betsileo and $M$. laevigata species groups. Zootaxa 1501, 31-44.

Raxworthy, C.J., Nussbaum, R.A., 1995. Systematics, speciation and biogeography of the dwarf chameleons (Brookesia, Reptilia, Squamata, Chamaeleontidae) of northern Madagascar. J. Zool. 235, 525-558.

Ray, N., 2005. PATHMATRIX: a GIS tool to compute effective distances among samples. Mol. Ecol. Notes 5, $177-180$.

Rogers, A.R., Harpending, H., 1992. Population growth makes waves in the distribution of pairwise genetic differences. Mol. Biol. Evol. 9, 552-569.

Rozas, J., Sánchez-Del Barrio, J.C., Messeguer, X., Rozas, R., 2003. DNASP, DNA polymorphism analyses by the coalescent and other methods. Bioinformatics 19 2496-2497.

Templeton, A.R., Crandall, K.A., Sing, C.F., 1992. A cladistic analysis of phenotypic associations with haplotypes inferred from restriction endonuclease mapping and DNA sequence data. III. Cladogram estimation. Genetics 132, 619-633.

Vences, M., Glaw, F., Böhme, W., 1999. A review of the genus Mantella (Anura, Ranidae, Mantellinae): taxonomy, distribution and conservation of Malagasy poison frogs. Alytes 17, 3-72.

Vences, M., Kosuch, J., Lötters, S., Widmer, A., Jungfer, K.H., Köhler, J., Veith, M., 2000. Phylogeny and classification of poison frogs (Amphibia: Dendrobatidae), based on mitochondrial $16 \mathrm{~S}$ and $12 \mathrm{~S}$ ribosomal RNA gene sequences. Mol. Phyl. Evol. 15, 34-40.

Vences, M., Aprea, G., Capriglione, T., Andreone, F., Odierna, G., 2002. Ancient tetraploidy and slow molecular evolution in Scaphiophryne: ecological correlates of speciation mode in Malagasy relict amphibians. Chromosome Res. 10, 127-136.

Vences, M., Thomas, M., Bonett, R.M., Vieites, D.R., 2005. Deciphering amphibian diversity through DNA barcoding: chances and challenges. Philos. Trans. R. Soc. London B, Biol. Sci. 360, 1859-1868.

Yoshioka, K., 2002. KyPlot - a user-oriented tool for statistical data analysis and visualisation. Comput. Stat. 17, 425-437.

Weir, B.S., Cockerham, C.C., 1984. Estimating $F$-statistics for the analysis of population structure. Evolution 38, 1358-1370.

Wilmé, L., Goodman, S.M., Ganzhorn, J.U., 2006. Biogeographic evolution of Madagascar's microendemic biota. Science 312, 1063-1065.

Wright, S., 1943. Isolation by distance. Genetics 28, 114-138. 